\title{
EVOLUCIÓN Y ANÁLISIS DE LA DEUDA PÚBLICA EN ESPAÑA. PERIODO 1996-2015
}

\author{
Vanesa Monge-Antolin
}


Panorama Económico, 24 (Octubre 2016 - Septiembre 2017), pp. 49-70

Vanesa Monge-Antolin

\title{
Evolución y análisis de la deuda pública en España. Periodo 1996-2015
}

\section{Resumen}

Este artículo muestra la evolución de las partidas y los instrumentos de financiación de manera pormenorizada de la deuda pública en España durante el periodo 1996-2015. Según la revisión de los Boletines Oficiales de Deuda del Banco de España, se observó que las partidas de deuda pública han aumentado considerablemente hasta encontrar un diferencial estadísticamente significativo en muchas de ellas y con una variabilidad más alta cuando gobierna el Partido Popular de corte conservadorliberal. Estos resultados se muestran a través de un estudio exploratorio, descriptivo y comparativo en relación a dos factores coyunturales: partido político en el poder y fase del ciclo económico.

Palabras Clave: Ciclo Económico, deuda pública, instrumentos de financiación de la Deuda pública, partidos políticos.

Clasificación JEL: H60, H63, H68.

\section{Analysis and evolution of the Spanish public debt (1996-2015)}

\begin{abstract}
This article presents a detailed evolution of the items and financing instruments of the Spanish public debt between 1996 and 2015. According to the revision of the Official Bulletins of Debt of the Bank of Spain, it was observed that the public debt items have increased considerably to the point where it is observably a statistically significant differential in many of them and with higher variability when the conservative-liberal Popular Party rules. These results are presented through an exploratory, descriptive and comparative study regarding two relevant factors: the political party in power and the economic cycle phase.
\end{abstract}

Keywords: Economic cycle, public, debt, financing instruments of public debt, political parties.

JEL Classification: H60, H63, H68.

\section{Évolution et analyse de la dette publique en espagne (1996-2015)}

\section{Résumé}

Cet article présente une évolution détaillée des parts et des instruments de financement de la dette publique espagnole entre 1996 et 2015. D'après la révision des Bulletins Officiels de la dette de la Banque d'Espagne, on a pu observer que les parts de la dette publique ont considérablement augmenté au point de constituer une différence statistiquement significative dans un grand nombre d'entre eux ( $p>$.05) et avec une variabilité d'autant plus élevée lorsque gouverne le Parti Populaire de tendance libéro-conservatrice. Les résultats sont présentés à travers une étude exploratoire, descriptive et comparative concernant deux facteurs importants : le parti politique au pouvoir et la phase du cycle économique.

Mots-clés: Cycle économique, dette publique, instruments de financement de la dette publique, partis politiques.

Nomenclature JEL: H60, H63, H68. 
Artículo de Investigación

\section{EVOLUCIÓN Y ANÁLISIS DE LA DEUDA PÚBLICA EN ESPAÑA. PERIODO 1996-2015}

INFORMACIÓN DEL ARTÍCULO

Recepción de artículo: 3 de febrero de 2016

Concepto de evaluación: 20 de junio de 2016

Aceptación de artículo: 25 de Julio de 2016

Vanesa Monge-Antolin

Universidad Nacional de Educación a Distancia, España

\section{INTRODUCCIÓN}

El problema del endeudamiento de los Estados y de las crisis de deuda pública, no es un problema nuevo, ni poco estudiado, al contrario, es muy prolijo en publicaciones, son tantas que resulta casi imposible realizar un análisis pormenorizado debido a la gran cantidad de ellas. La obra de referencia que presenta la definición moderna de las deudas de Estado fue realizada por Alexander N. Sack en 1927. Según Sack: "Las deudas de Estado deben ser incurridas por los servicios competentes del gobierno de manera conforme a la ley".

El autor mencionado sentó las bases del derecho financiero, además en su obra realiza un recorrido histórico sobre las deudas de los estados y presenta un tratado en el cual apunta a las diferentes casuísticas de transferencia de deudas y los problemas derivados de las mismas en el caso de que se produzcan cambios de poder, o un Estado sufra transformaciones territoriales: anexión o disminución territorio y la desaparición o creación de un Estado.

El caso de estudio que nos ocupa este artículo es España, y el problema del excesivo endeudamiento de deuda pública es reciente en la última década, no así en la historia, ya que a lo largo de la misma, España ha presentado suspensión de pagos en 14 veces como indican José M. Domínguez y Rafael López del Paso (2011). Pese a ello, durante los últimos ocho años, el montante de deuda pública se ha disparado hasta superar casi el millón de euros -ver tabla 1-.

\footnotetext{
${ }^{1}$ Autor para correspondencia. Correo electrónico: mmonge41@alumno.uned.es
} 
Es común que en el estudio de las crisis de deuda, se haga referencia a los manuales actuales más difundidos Reinhart y Rogoff (2009), Tomás Piketty (2013), Xabier Arrizabalo Montoro (2014) y a Carlos Álvarez-Nogal (2015), en lo que se refiera a periodos de crisis que nos ofrezcan una visión histórica de los problemas y que cuentan hay elementos comunes en todas ellas que se repiten en el tiempo. La excesiva acumulación de deuda a gran escala conlleva un riesgo muy alto, sobre todo en los tiempos de crisis.

Para entender el sobre-endeudamiento reciente de España y la afectación que tuvo en el mismo la crisis financiera, hay que realizar un pequeño viaje histórico en el tiempo que explique las consecuencias y los cambios de la estructura de la deuda pública española desde la creación de la Unión Monetaria Europea ${ }^{1}$-UME-. Si bien, la crisis financiera de 2007 generó la mayor recesión global reciente, ésta no afectó de manera igual a todos los países que conforman la Unión Europea debido a las diferentes estructuras productivas de los países que la integran.

Hay que entender que El Tratado de Maastricht ${ }^{2}$ firmado en 1992, sentó las bases de lo que se llaman "políticas de convergencia económica" entre los

1 La UME -Unión Monetaria Europea-, existe desde el 4 de enero de 1999 éste se puso en circulación como moneada y billetes de curso legal el 1 de enero de 2002. Esta unión ejecuta la política monetaria en la zona euro. Como sabemos, las dos principales funciones del BCE son: 1) el control de la inflación en la eurozona y 2) Favorecer las operaciones de financiación e inversión a corto plazo de los diferentes agentes que componen el mercado financiero, dentro de un contexto adecuado.

2 El Tratado de la Unión Monetaria Europea firmado en Maastricht 1992. La moneda única se decidió en 1995 en una cumbre de dirigentes europeos celebrada en Madrid, con el nombre de "euro". Durante los siguientes años, y previamente a que el BCE se hiciera cargo de las políticas económicas se puso en marcha el Instituto Monetario Europeo -con sede en Frankfurt-. países firmantes y la creación del espacio monetario único. Los países que firmaron al Tratado deben integrar crecimiento económico y como apunta Larraga (2008 p.24) "una cultura de estabilidad especialmente centrada en el crecimiento controlado de los precios; donde se plantea la creación de una moneda única y de una institución con plena soberanía en materia de política monetaria". De esta forma nació el mercado monetario europeo ${ }^{3}$, que es el conjunto de mercados financieros donde se negocia el dinero y los activos financieros a corto plazo.

Desde la entrada de España en la UME, se ha producido un proceso de segmentación de mercados, así, como señala Larraga, han surgido una gran cantidad de plataformas de negociación de deuda no organizadas, en las que algunos creadores de mercado como JP Morgan, Deutsche Bank fomentan la negociación de la deuda pública. La nueva regulación del mercado de deuda pública en anotaciones española (2005), plantea cambios en la estructura de los miembros de mercado español de deuda pública. Por ello, tras la reforma ya no habrá distinciones institucionales entre entidades. La capacitación para operar en el mercado será establecida por los estatutos de la propia entidad, y esta capacitación será otorgada por el Ministerio de Economía y Hacienda a propuesta del Bando de España, previo informe de la Comisión Nacional del Mercado de Valores.

\footnotetext{
3 En este mercado se negocian los activos financieros: Dinero, activos de caja y depósitos interbancarios. Letras del Tesoro. Pagarés de empresa, bancarios, corporativos y autonómicos. Bonos y Obligaciones del Estado o privados con vencimiento residual interior a 18 meses. Repos y simultáneas. Forwards sobre activos monetarios. FNRs. Bonos de titularizaciones hipotecarias o de otros activos con cupones variables. Cédulas hipotecarias de vencimiento residual inferior a 18 meses. Derivados sobre tipos de interés a corto (Forwards, futuros, opciones y swaps) y Participaciones de inversión monetarias (antes denominados FIAMM).
} 
El objetivo de este artículo es mostrar de manera pormenorizada la evolución de las partidas de Deuda Pública antes de la creación de la UME (1999) hasta llegar al periodo actual, motivo por el cual se elige el periodo 1996-2015. Durante este periodo se podrán analizar, estudiar y comparar la evolución de las partidas para medir el impacto de las mismas en el tiempo y compararlas con dos factores coyunturales: partido político en el poder (socialista-progresista -PSOE- o liberal-conservador -PP-) y la fase del ciclo económico (recesión, expansión, recuperación).

Así resulta interesante ver cómo estos resultados dibujan un panorama contrario a lo que se debería considerar como políticas liberales, ya que el partido político que más deuda pública ha emitido es de corte conservador-liberal (PP).

Este documento se divide en tres secciones, sin incluir la introducción. La primera presenta la metodología empleada para la realización del estudio de manera pormenorizada, procedimiento empírico y fuente de datos. La segunda presenta las definiciones de los instrumentos de deuda que seanalizan, para seguidamente mostrar los resultados de los análisis realizados. Por último, se presenta el espacio de discusión de los resultados obtenidos en el cual nos plantearemos sobre las particularidades identificadas en el análisis, los efectos de las partidas de coyuntura y su relación con las partidas de deuda.

\section{METODOLOGIA EMPLEADA}

\subsection{Materiales y Método}

Para el análisis estadístico se ha empleado la aplicación informática SPSS-234. Las

4 IBM Corp. Released 2015. IBM SPSS Statistics v 23.0 for Windows; Armonk. NY. USA técnicas y test estadísticos empleados han sido:

- Descriptivos habituales para partidas cuantitativas: media, mediana, desviación estándar, con Test de Shapiro-Wilks de bondad de ajuste al modelo de la curva normal de Gauss.

- Test de diferencias ente medias Student, Anova, alternativas no paramétricas, etc...

- Estimación del tamaño del efecto (asociación entre partidas) mediante $\mathrm{R}^{2}$.

- Números índice. Gráficos de control.

- Métodos correlacionales: Pearson y Spearman.

- Análisis de regresión: modelos univariantes y multivariantes.

El nivel de significación ${ }^{5}$ fijado es el habitual 5\% (significativo si $\mathrm{P}<.05$ ) excepto en el test Shapiro-Wilks de bondad de ajuste, donde se consideran significativos solo los desvíos graves del modelo, es decir al $1 \%(\mathrm{P}<.01)$.

\subsection{Procedimiento empírico}

En primer lugar se procede a realizar una estadística descriptiva de todas las partidas recogidas para este estudio. Dada la naturaleza cuantitativa de las mismas, los descriptivos habituales son: media, mediana, desviación estándar, rango, etc. A ellos se han añadido los estadísticos exploratorios de la forma de la partida:

\footnotetext{
5 Nota acerca del número de casos. El tamaño del efecto "moderado" expresa diferencias que son reales y que se pueden detectar hasta con muestras tan pequeñas como $50<\mathrm{N}<100$. El tamaño del efecto pequeño es indicativo de que puede haber algo, pero para detectarlas con cierta seguridad se necesitarían muestras de alrededor de $\mathrm{N}=500$. El tamaño "grande" evidentemente son diferencias que existen con elevado grado de confianza y que detectan casi a "simple vista" y con muestras muy pequeñas. En este caso, N=20 (años) la muestra es muy pequeña, por lo que se necesitarán efectos muy grandes para poder detectarlos
} 
asimetría y curtosis (altura de la curva) junto a un test de bondad de ajuste con respecto a la campana normal de Gauss, en concreto el Test de Shapiro-Wilks específico e indicado cuando el número de datos de cada partida es inferior a 50, como en nuestro estudio ( $\mathrm{N}=20$, correspondiente a los 20 años recogidos). Este test de SW es un procedimiento inferencial que determina hasta qué punto una partida se asemeja o no campana de Gauss, se genera para ello un valor de probabilidad P. Si el valor de esta $\mathrm{P}$ de significación del test es superior al 5\% ( $p>05)$ no hay desvío significativo y se considera que la partida es normal; si la $\mathrm{P}$ es inferior al $5 \%$ pero superior al 1\% ( $p>$.01) hay desvío leve, de manera que se puede admitir una tendencia hacia la normalidad en la partida; pero si la P es inferior al $1 \%(\mathrm{p}<.01)$ el desvío es grave y la partida se aleja del citado modelo normal y en ese caso son los estadísticos de asimetría y curtosis los que nos indican el motivo y definen la forma de la partida. En estos estadísticos, el valor referencia de la normalidad es 0 y en torno a él los desvíos son mínimos dentro del intervalo [-0.50; +0.50] y son aceptables en el margen hasta llegar a la unidad [ \pm 1$]$. Es decir que los desvíos son notables fuera del intervalo $[-1 ;+1]$.

A continuación se presenta las tablas del resumen descriptivo y exploratorio de las partidas, agrupadas en bloques teóricos. Para definir la centralidad se ha utilizado los valores de la media y de la mediana; cuanto más simétrica sea la partida con respecto a esta centralidad, más similares serán los valores de ambos estadísticos. Para estudiar la variabilidad se han utilizado la desviación estándar (que es similar a una media de las distancias de cada valor hasta la media) y el rango intercuartil (que es la diferencia entre los valores que limitan al 50\% central de casos). En ambos, cuanto más alto sea el valor mayor es el grado de dispersión/ variabilidad entre unos valores y otros de la partida; y por ende cuanto menor sea el valor, más homogéneos (menor variación) tienes los valores una partida entre sí. En la misma línea, un bajo rango (mín. /máx.) indica menos variaciones en los valores.

A la par de la descriptiva de esta partidas cuantitativas de gasto y dada la obvia influencia que sobre ellas debe de ejercer tanto el Partido Político en el Gobierno como la Fase de ciclo económico en la que los datos se recogen, se ha procedido a realizar test de contraste de diferencia entre medias para determinar la existencia o no de diferencias que se puedan considerar como estadísticamente significativas (al menos al 5\%: $\mathrm{p}<.05$ ). Los test estadísticos más potentes para este tipo de contrastes son: la $\mathrm{T}$ de Student (cuando se comparan dos medias en función del partido político) y el Análisis de Varianza -Anova- (cuando se comparan más de dos medias, en función de la fase económica). Ambos test además, permiten la estimación del tamaño del efecto con $\mathrm{R}^{2}$, un útil índice evaluador de la magnitud de estas diferencias. En rigor, este tipo de técnicas estadísticas exigen la normalidad de las partidas cuantitativas a comparar; sin embargo la experiencia demuestra que el incumplimiento de esta condición no suele tener efectos sobre los resultados, salvo en situaciones de grandes asimetrías. Los test alternativos para estos casos son de tipo no paramétrico, en concreto: el Test U de Mann-Whitney y el $\mathrm{H}$ de KruskalWallis, respectivamente. Ante lo pequeño de la muestra, se ha optado por doblar cada contraste, y se aplican ambos test alternativos: Student/MW ó Anova/KW según el factor, con 2 ó con más de 2 medias, a comparar. Esta duplicación del análisis pretende solo aumentar la confiabilidad 
estadística, en tanto que la similitud de los resultados y la coincidencia de las conclusiones estadísticas, nos permitan ganar en seguridad en el caso de falta de las condiciones adecuadas en rigor.

En resumen, en los análisis que siguen, se van a explorar y describir las partidas cuantitativas, para proceder a su contraste en función de los factores coyunturales: partido político y fase económica ${ }^{6}$.

\subsection{Fuente de datos}

El periodo de datos recogidos abarca del 1996 a 2015. Sin embargo no se tienen datos del periodo completo de todas las partidas. De algunas, como por ejemplo el de la Deuda Pública solo se podrá analizar el periodo 1998-2015. Los datos utilizados en este estudio proceden de fuentes oficiales facilitadas por el Gobierno de España, en concreto corresponden a los datos facilitados por el Tesoro Público Español y del Boletín Oficial de Deuda del Banco de España.

\section{RESULTADOS}

\subsection{Análisis Exploratorio, Descriptivo y Comparativo de la Deuda Publica en España 1996-2015.}

En este primer apartado se presenta el análisis de la Deuda Pública de España. Para ello se procede a aclarar algunos de los conceptos, es imprescindible citar el Convenio de Creadores de Mercado7, así como el Real Decreto 38/1997 de 17 de enero, por el que se dispone la creación de Deuda Publica durante 1997 y enero de

6 Estos resultados se acompañan de la estimación del tamaño del efecto con el coeficiente R2.

7 Resolución de 20 de julio de 2012 de la Secretaría General del Tesoro y Política Financiera (BOE del día 26 de julio de 2012) y sus posteriores modificaciones.
1998, que faculta al Ministro de Economía y Hacienda a autorizar la segregación del principal y cupones de determinadas emisiones de Deuda del Estado, así como su posterior reconstitución a efectos de su negociación en los mercados secundarios. Este mismo Real Decreto hace mención al artículo 104.1 de la Ley General Presupuestaria ${ }^{8}$, en la que se autoriza al Ministro de Economía y Hacienda a proceder a la emisión o contracción de la Deuda Pública, establece su representación voluntaria o exclusiva en anotaciones en cuenta, títulos-valores u otros que de manera formal la reconozca; señalar o concertar su plazo, tipos de interés y demás características, y formalizar en su caso en representación del Estado tales operaciones.

- La deuda pública en circulación o deuda soberana. Deuda emitida por el Estado o las Administraciones Públicas territoriales, Organismos Públicos y Empresas Públicas, con el fin de financiar sus actividades.

- La deuda del estado o el nominal en circulación. Muestra el importe nominal de la deuda viva a fin de cada periodo, actualizado en las deudas Indexadas por el coeficiente de indexación correspondiente. A partir de enero de 1999, incluye la Deuda emitida en monedas de países de la UME.

- La deuda segregada o Strips ${ }^{9}$ de deuda. Según el artículo 1 del Real Decreto 38/1997, la segregación es la operación por la que se da de

8 Aprobado por Real Decreto Legislativo 1091/1988. de 23 de septiembre.

9 Los strips son las siglas que corresponden al acrónimo "Separately trade registered interest principal securities". 
baja en la Central de Anotaciones un Bono segregable ${ }^{10}$ asentándose en su lugar nuevos valores con rendimiento implícito, procedentes todos ellos de los flujos de caja correspondientes a sus cupones y el principal de dicho Bono ${ }^{11}$.

Los strips nacen en junio de 1997 tras varios años de debates y negociaciones entre los miembros del mercado de Deuda Pública, el Banco de España y el Tesoro Público, pero no será hasta enero de 1998 cuando se inicia la operativa de segregación y reconstitución de bonos. Un bono segregable se puede segregar ${ }^{12}$ en base a dar de baja dicho bono en la Central de anotaciones y dar de alta el conjunto de cupones cero que lo integran. Según Larraga: "Los strips permiten realizar operaciones de inversión sin riesgo de reinversión y, con ello, establecer estrategias de inmunización en fondos de inversión garantizados, así como llevar a cabo operaciones de inversión con mayor

10 Según el artículo 1.e del Real Decreto 37/1998 un Bono segregable: Bono u Obligación del Estado en cuyas convocatorias de emisión la Dirección General del Tesoro y Política Financiera hubiere autorizado la posibilidad de segregación y reconstitución de sus flujos de caja.

11 El Tesoro Público emite valores (Bonos y obligaciones) con vencimiento a un plazo mayor de dos años, éstos suelen ser iguales en todas sus características, la única diferencia que hay es en relación al plazo, que puede ir de los 2 a los 5 años. Éstos se emiten mediante subasta pública competitiva. El valor nominal mínimo en la subasta es de 1000 euros y las peticiones de los importes han de ser múltiplos de 1000. En la página web del Tesoro encontramos las características generales que tiene un Bono u Obligación. Anualmente se presenta el calendario de subastas de éstos bonos y obligaciones y ésta emisión se puede llevar a cabo en diferentes subastas, por tanto el bono se subastará a diferentes precios y tasas de rentabilidad.

12 Equivale a despedazar o descomponer un bono, se entiende mejor con el siguiente ejemplo: De hecho segregar un bono a 5 años es convertir un bono con $n$ (5) cupones periódicos en $n+1$ (6) cupones cero. El principio de que la suma de las partes integrantes del bono debe ser igual al valor entero del mismo permite generar operaciones de arbitraje entre strips y bonos enteros, tanto de segregación como de reconstitución. grado de apalancamiento". En el mercado de deuda pública solo los creadores de mercado están autorizados a segregar o reconstituir bonos. Salvo mercados de deuda pública de alto grado de liquidez como el norteamericano o el francés, es frecuente que los mercados de strips presentes bajo volúmenes de contratación y escasa liquidez, si bien ello no invalida su utilización ni la función para la que han sido diseñados.

- La deuda pública no segregada. Al contrario que la anterior, es la cantidad de deuda sin "descomponer" o "entera".

Los resultados obtenidos son muy similares para las cuatro partidas de deuda analizadas. Todas ellas presentan un desvío altamente significativo con respecto a la normal $(\mathrm{p}<.01)$ debido a un cierto grado de asimetría positiva, es decir con una mayor presencia de valores por debajo de las medias respectivas, aunque los que la superan se alejan más de ellas y elevan su valor de forma notable con respecto a las medianas. Se muestra el análisis en comparación al PIB y a la Deuda Total.

Cuando se analiza las partidas anteriores sobre el ratio del PIB y la Deuda Total, en todas ellas se produce un claro desvío significativo $(\mathrm{p}<.01)$ respecto a la normal, a pesar de que la asimetría es negativa existe una tendencia hacia la normalidad. Esto es normal que ocurra, ya que al comparar las partidas en ratios el efecto disminuye.

La justificación para medir la influencia del partido político en la emisión de deuda, y su atribución en el aumento o disminución de la misma tiene que ver con el propio sistema de funcionamiento democrático de España. Para ello, hay que hacer referencia a la Constitución Española vigente de 1978, a la Ley General Presupuestaria y a 
Tabla 1: Análisis exploratorio y descriptivo. Deuda Publica en España 1996-2015

\begin{tabular}{|c|c|c|c|c|c|c|c|c|}
\hline \multirow[b]{2}{*}{ Partida } & \multicolumn{2}{|c|}{ Centralidad } & \multirow{2}{*}{$\begin{array}{c}\text { Rango } \\
\text { (Mín. / Máx.) }\end{array}$} & \multicolumn{2}{|c|}{ Variabilidad } & \multirow[b]{2}{*}{ Asimetría } & \multirow[b]{2}{*}{ Curtosis } & \multirow{2}{*}{$\begin{array}{l}\text { Test SW: } \\
\text { p valor }\end{array}$} \\
\hline & Media & Mediana & & $\begin{array}{l}\text { Desviación } \\
\text { estándar }\end{array}$ & $\begin{array}{c}\text { Rango } \\
\text { intercuartil }\end{array}$ & & & \\
\hline $\begin{array}{l}\text { D. Pública } \\
\text { Circulación }\end{array}$ & 471491.66 & 347131.63 & $\begin{array}{l}256079.14 / \\
900650.24\end{array}$ & 217436.84 & 356533.06 & 0.90 & -0.72 & .004 \\
\hline D. del Estado & 438271.21 & 306477.62 & $\begin{array}{l}241801.39 / \\
852212.93\end{array}$ & 204871.26 & 327097.54 & 0.93 & -0.66 & .002 \\
\hline D. No segregada & 407228.40 & 284569.66 & $\begin{array}{l}229817.60 / \\
787788.60\end{array}$ & 189035.19 & 303175.39 & 0.92 & -0.70 & .002 \\
\hline D. Segregada & 31042.81 & 24205.91 & $\begin{array}{c}11983.80 / \\
64424.33\end{array}$ & 16092.76 & 23922.01 & 1.05 & -0.15 & .007 \\
\hline
\end{tabular}

Tabla 2 : Análisis exploratorio y descriptivo. Ratio sobre PIB y sobre la Deuda Total.

\begin{tabular}{|c|c|c|c|c|c|c|c|c|}
\hline \multirow[b]{2}{*}{ Partida } & \multicolumn{2}{|c|}{ Centralidad } & \multirow{2}{*}{$\begin{array}{c}\text { Rango } \\
\text { (Mín. / Máx.) }\end{array}$} & \multicolumn{2}{|c|}{ Variabilidad } & \multirow[b]{2}{*}{ Asimetría } & \multirow[b]{2}{*}{ Curtosis } & \multirow{2}{*}{$\begin{array}{l}\text { Test SW: } \\
\text { p valor }\end{array}$} \\
\hline & Media & Mediana & & $\begin{array}{l}\text { Desviación } \\
\text { estándar }\end{array}$ & $\begin{array}{c}\text { Rango } \\
\text { intercuartil }\end{array}$ & & & \\
\hline $\begin{array}{l}\text { \% D. Pública } \\
\text { Circulac. / PIB } \\
\end{array}$ & 50.44 & 45.66 & 32.42 / 83.30 & 16.59 & 25.05 & 1.00 & -0.28 & .011 \\
\hline $\begin{array}{l}\text { \% D. del Estado } \\
\text { / D. Total }\end{array}$ & 92.85 & 93.57 & 86.99 / 95.35 & 2.35 & 2.57 & -1.37 & 1.12 & .006 \\
\hline $\begin{array}{l}\text { \% D. No segregada } \\
\text { / D. Tot.al }\end{array}$ & 86.38 & 86.89 & 79.76 / 89.74 & 2.56 & 2.52 & -1.28 & 1.50 & .042 \\
\hline $\begin{array}{l}\text { \% D. Segregada } \\
\text { / D. Total }\end{array}$ & 6.47 & 6.62 & $4.68 / 7.36$ & 0.67 & 0.57 & -1.45 & 2.58 & .015 \\
\hline
\end{tabular}

los Presupuestos Generales del Estado que cada año limitan la cifra máxima de endeudamiento neto a generar de un ejercicio a otro. Por ello, en enero de cada año se presenta a través del organismo oficial correspondiente -Ministerio de Economía y Dirección General del Tesoroel calendario y determinan la política de emisión a seguir durante ese año. Esta lleva la forma jurídica de Real Decreto y se desarrolla en Órdenes Ministeriales y Resoluciones administrativas que salen publicadas en el Boletín Oficial del Estado. Al mismo tiempo, el Banco de España debe ejercer de supervisor del mercado financiero de deuda pública. De esta manera se comprende con mayor claridad, la influencia del partido político en el poder y la repercusión de las políticas de deuda públicas realizadas anualmente. A continuación se realizan los Test de contraste de estas partidas con los factores de coyuntura: partido político y ciclo económico que se muestran en las tablas 3 y 4.

En los contrastes obtenidos, en ninguna de las 4 partidas que se muestran en la Tabla 3, existen diferencias observadas entre PP y PSOE y se puede considerar éstas como estadísticamente significativas ( $p>$.05), donde también se puede observar una mayor homogeneidad de valores cuando gobierna el PSOE, en tanto que en el caso del PP hay mucha más variabilidad. Hecho que influye en los resultados que se muestran al comprar en función de la Fase económica.

En el análisis de diferencia de medias, en todas las partidas, las medias del PP son superiores a las medias con el PSOE, sin embargo en el \% de Deuda Pública Circulación / PIB la diferencia no es significativa aunque por escaso margen y se podría decir que es casi significativa 
Tabla 3: Análisis comparativo. Test de deferencia entre las medias.

Deuda, en función del Partido en el Gobierno

\begin{tabular}{|c|c|c|c|c|c|c|c|c|c|}
\hline \multirow{2}{*}{ Partida } & \multirow{2}{*}{ Categoría del Factor } & \multicolumn{3}{|c|}{ Valores descriptivos } & \multicolumn{2}{|c|}{ Student } & \multirow{2}{*}{ Efecto: $\mathbf{R}^{2}$} & \multicolumn{2}{|c|}{ Mann-Whitney } \\
\hline & & $\mathbf{N}$ & Media & D.E. & $/ \mathrm{t} /$ & $\mathbf{P}$ & & /Z/ & $\mathbf{P}$ \\
\hline \multirow{2}{*}{ D. Pública Circul. } & Gobierno del PP & 10 & 499343.13 & 274039.88 & \multirow{2}{*}{0.60} & \multirow{2}{*}{$.560 \mathrm{NS}$} & \multirow{2}{*}{.022} & \multirow{2}{*}{0.71} & \multirow{2}{*}{$.515^{\mathrm{NS}}$} \\
\hline & Gobierno del PSOE & 8 & 436677.31 & 125587.28 & & & & & \\
\hline \multirow{2}{*}{ D. del Estado } & Gobierno del PP & 10 & 469193.86 & 255439.55 & \multirow{2}{*}{0.70} & \multirow{2}{*}{$.491^{\mathrm{NS}}$} & \multirow{2}{*}{.030} & \multirow{2}{*}{0.71} & \multirow{2}{*}{$.515 \mathrm{NS}$} \\
\hline & Gobierno del PSOE & 8 & 399617.89 & 122339.64 & & & & & \\
\hline \multirow{2}{*}{ D. no segregada } & Gobierno del PP & 10 & 435663.26 & 234950.48 & \multirow{2}{*}{0.70} & \multirow{2}{*}{$.492^{\mathrm{NS}}$} & \multirow{2}{*}{.030} & \multirow{2}{*}{0.71} & \multirow{2}{*}{$.515^{\mathrm{NS}}$} \\
\hline & Gobierno del PSOE & 8 & 371684.81 & 114938.12 & & & & & \\
\hline \multirow{2}{*}{ D. Segregada } & Gobierno del PP & 10 & 33530.60 & 20590.52 & \multirow{2}{*}{0.72} & \multirow{2}{*}{$.492^{\mathrm{NS}}$} & \multirow{2}{*}{.032} & \multirow{2}{*}{0.62} & \multirow{2}{*}{$.573^{\mathrm{NS}}$} \\
\hline & Gobierno del PSOE & 8 & 27933.08 & 7996.67 & & & & & \\
\hline
\end{tabular}

N.S. $=$ NO significativo $(\mathrm{P}>05)$

Tabla 4: Análisis comparativo. Test de deferencia entre las medias. $\%$ de Deuda, en función del Partido en el Gobierno

\begin{tabular}{|c|c|c|c|c|c|c|c|c|c|}
\hline \multirow{2}{*}{ Partida } & \multirow{2}{*}{ Categoría del Factor } & \multicolumn{3}{|c|}{ Valores descriptivos } & \multicolumn{2}{|c|}{ Student } & \multirow{2}{*}{$\begin{array}{l}\text { Efecto: } \\
\mathbf{R}^{2}\end{array}$} & \multicolumn{2}{|c|}{$\begin{array}{l}\text { Mann- } \\
\text { Whitney }\end{array}$} \\
\hline & & $\mathrm{N}$ & Media & D.E. & $/ \mathrm{t} /$ & $\mathbf{P}$ & & /Z/ & $\mathbf{P}$ \\
\hline \multirow{2}{*}{$\begin{array}{l}\text { \% D. Pública } \\
\text { Circulac. / PIB }\end{array}$} & Gobierno del PP & 10 & 57.02 & 18.12 & \multirow{2}{*}{2.05} & \multirow{2}{*}{$.057^{\mathrm{NS}}$} & \multirow{2}{*}{.208} & \multirow{2}{*}{1.96} & \multirow{2}{*}{$.055^{\mathrm{NS}}$} \\
\hline & Gobierno del PSOE & 8 & 42.21 & 10.34 & & & & & \\
\hline \multirow{2}{*}{$\begin{array}{l}\text { \% D. del Estado } \\
\text { / D. Total }\end{array}$} & Gobierno del PP & 10 & 94.21 & 0.88 & \multirow{2}{*}{3.56} & \multirow{2}{*}{$.003^{* *}$} & \multirow{2}{*}{.442} & \multirow{2}{*}{2.89} & \multirow{2}{*}{$.002^{* *}$} \\
\hline & Gobierno del PSOE & 8 & 91.15 & 2.54 & & & & & \\
\hline \multirow{2}{*}{$\begin{array}{l}\text { \% D. No segregada } \\
\text { / D. Total }\end{array}$} & Gobierno del PP & 10 & 87.71 & 1.29 & \multirow{2}{*}{2.99} & \multirow{2}{*}{$.009^{* *}$} & \multirow{2}{*}{.359} & \multirow{2}{*}{2.31} & \multirow{2}{*}{$.021^{*}$} \\
\hline & Gobierno del PSOE & 8 & 84.71 & 2.84 & & & & & \\
\hline \multirow{2}{*}{$\begin{array}{l}\text { \% D. Segregada } \\
\text { / D. Total }\end{array}$} & Gobierno del PP & 10 & 6.49 & 0.73 & \multirow{2}{*}{0.55} & \multirow{2}{*}{$.864^{\mathrm{NS}}$} & \multirow{2}{*}{.002} & \multirow{2}{*}{0.27} & \multirow{2}{*}{$.811^{\mathrm{NS}}$} \\
\hline & Gobierno del PSOE & 8 & 6.44 & 0.62 & & & & & \\
\hline
\end{tabular}

N.S. $=$ NO significativo $(\mathrm{P}>.05)^{*}=$ Significativo al $5 \%(\mathrm{P}<.05)^{* *}=$ Altamente significativo al $1 \%(\mathrm{P}<.01)$

(p<.10); de hecho se aprecia un tamaño del efecto (.208) que es moderado y que podría indicarnos que en muestras con mayor $\mathrm{N}$ sí que habría significación. Por otro lado en el \% de Deuda segregada / deuda total, la diferencia no puede ser considerada como significativa de forma sólida ( $p>$.05). En las otras dos partidas, las diferencias sí que son significativas. El \% de Deuda del Estado / D. total $(\mathrm{p}<.01)$ con tamaño del efecto grande. Y en el \% de Deuda no segregada / D. total, en ambos casos existe relación en cuanto al partido político que hay en el gobierno, es más alto con el PP que con el PSOE.

Se muestra ahora al análisis comparativo de las partidas de deuda y se realiza el Test de diferencia de medias en relación a la Fase del Ciclo Económico -tablas 5 y 6-.
Por su parte los contrastes en función de la Fase del ciclo económico se muestran en la tabla 5 , se han encontrado que en las 4 partidas se han detectado diferencias que son estadísticamente significativas ( $\mathrm{p}<.01)$ y con tamaños del efecto muy grandes $(>.800)$ tales que los valores se han ido creciendo con el paso de los años, ya que la media es menor en los años de la fase expansiva (además con mucha homogeneidad), se incrementa de manera notable en los años de recesión (si bien hay alta variabilidad) y siguen creciendo aunque en menor medida en los dos últimos años de recuperación.

En cuanto al análisis comparativo del test de diferencia entre las medias de las partidas de deuda en relación al ratio en 
Tabla 5: Análisis comparativo. Test de deferencia entre las medias. Deuda, en función de la Fase del ciclo económico

\begin{tabular}{|c|c|c|c|c|c|c|c|c|c|}
\hline \multirow{2}{*}{ Partida } & \multirow{2}{*}{ Categoría del Factor } & \multicolumn{3}{|c|}{ Valores descriptivos } & \multicolumn{2}{|c|}{ Anova } & \multirow{2}{*}{ Efecto: $\mathbf{R}^{2}$} & \multicolumn{2}{|c|}{ Kruskal-Wallis } \\
\hline & & $\mathrm{N}$ & Media & D.E. & $/ F /$ & $P$ & & $\mathrm{Chi}^{2}$ & $\mathbf{P}$ \\
\hline \multirow{3}{*}{ D. Pública Circ. } & Fase expansiva & 10 & 309864.36 & 30021.12 & \multirow{3}{*}{48.08} & \multirow{3}{*}{$.000^{* *}$} & \multirow{3}{*}{.865} & \multirow{3}{*}{13.47} & \multirow{3}{*}{$.001^{* *}$} \\
\hline & Fase de recesión & 6 & 606595.58 & 140678.04 & & & & & \\
\hline & Fase de recuperación & 2 & 874316.34 & 37241.76 & & & & & \\
\hline \multirow{3}{*}{ D. del Estado } & Fase expansiva & 10 & 286985.29 & 21120.12 & \multirow{3}{*}{47.88} & \multirow{3}{*}{$.000^{* *}$} & \multirow{3}{*}{.865} & \multirow{3}{*}{13.47} & \multirow{3}{*}{$.001^{* *}$} \\
\hline & Fase de recesión & 6 & 562206.78 & 134826.03 & & & & & \\
\hline & Fase de recuperación & 2 & 822894.06 & 41463.15 & & & & & \\
\hline \multirow{3}{*}{ D. no segregada } & Fase expansiva & 10 & 266988.49 & 17712.46 & \multirow{3}{*}{48.41} & \multirow{3}{*}{$.000^{* *}$} & \multirow{3}{*}{.866} & \multirow{3}{*}{13.47} & \multirow{3}{*}{$.001^{* *}$} \\
\hline & Fase de recesión & 6 & 523550.72 & 124146.30 & & & & & \\
\hline & Fase de recuperación & 2 & 759460.94 & 40061.37 & & & & & \\
\hline \multirow{3}{*}{ D. Segregada } & Fase expansiva & 10 & 19996.80 & 3669.69 & \multirow{3}{*}{37.34} & \multirow{3}{*}{$.001^{* *}$} & \multirow{3}{*}{.833} & \multirow{3}{*}{12.92} & \multirow{3}{*}{$.002^{* *}$} \\
\hline & Fase de recesión & 6 & 38656.07 & 110747.87 & & & & & \\
\hline & Fase de recuperación & 2 & 63433.12 & 1401.78 & & & & & \\
\hline
\end{tabular}

${ }^{* *}=$ Altamente significativo al $1 \%(\mathrm{P}<.01)$

Tabla 6: Análisis comparativo. Test de deferencia entre las medias. \% de Deuda, en función de la Fase del ciclo económico

\begin{tabular}{|c|c|c|c|c|c|c|c|c|c|}
\hline \multirow{2}{*}{ Partida } & \multirow{2}{*}{ Categoría del Factor } & \multicolumn{3}{|c|}{ Valores descriptivos } & \multicolumn{2}{|c|}{ Anova } & \multirow{2}{*}{ Efecto: $\mathbf{R}^{2}$} & \multicolumn{2}{|c|}{ Kruskal-Wallis } \\
\hline & & $\mathbf{N}$ & Media & D.E. & $/ F /$ & $\mathbf{P}$ & & $\mathrm{Chi}^{2}$ & $\mathbf{P}$ \\
\hline \multirow{3}{*}{$\begin{array}{l}\text { \% D. Pública } \\
\text { Circulac. / PIB }\end{array}$} & Fase expansiva & 10 & 40.10 & 5.09 & \multirow{3}{*}{19.26} & \multirow{3}{*}{$.000^{* *}$} & \multirow{3}{*}{.720} & \multirow{3}{*}{9.58} & \multirow{3}{*}{$.008^{* *}$} \\
\hline & Fase de recesión & 6 & 57.02 & 14.67 & & & & & \\
\hline & Fase de recuperación & 2 & 82.38 & 1.31 & & & & & \\
\hline \multirow{3}{*}{$\begin{array}{l}\text { \% D. del Estado / } \\
\text { D. Total }\end{array}$} & Fase expansiva & 10 & 92.82 & 2.87 & \multirow{3}{*}{0.57} & \multirow{3}{*}{.724 NS } & \multirow{3}{*}{.042} & \multirow{3}{*}{1.79} & \multirow{3}{*}{$.408^{\mathrm{NS}}$} \\
\hline & Fase de recesión & 6 & 92.48 & 1.72 & & & & & \\
\hline & Fase de recuperación & 2 & 94.10 & 0.74 & & & & & \\
\hline \multirow{3}{*}{$\begin{array}{l}\text { \% D. No segregada / } \\
\text { D. Total }\end{array}$} & Fase expansiva & 10 & 86.42 & .324 & \multirow{3}{*}{0.05} & \multirow{3}{*}{$.952 \mathrm{NS}$} & \multirow{3}{*}{.007} & \multirow{3}{*}{0.68} & \multirow{3}{*}{$.713^{\mathrm{NS}}$} \\
\hline & Fase de recesión & 6 & 86.16 & 1.76 & & & & & \\
\hline & Fase de recuperación & 2 & 86.68 & 0.88 & & & & & \\
\hline \multirow{3}{*}{$\begin{array}{l}\text { \% D. Segregada / } \\
\text { D. Total }\end{array}$} & Fase expansiva & 10 & 6.41 & 0.70 & \multirow{3}{*}{1.74} & \multirow{3}{*}{.209 NS } & \multirow{3}{*}{.189} & \multirow{3}{*}{4.72} & \multirow{3}{*}{$.095^{\mathrm{NS}}$} \\
\hline & Fase de recesión & 6 & 6.31 & 0.59 & & & & & \\
\hline & Fase de recuperación & 2 & 7.26 & 0.15 & & & & & \\
\hline
\end{tabular}

N.S. $=$ NO significativo $(\mathrm{P}>.05)^{* *}=$ Altamente significativo al $1 \%(\mathrm{P}<.01)$ 
función de la Fase del ciclo económico se presentan los siguientes resultados:

El resumen de los resultados de los contrastes en función de la Fase del ciclo económico se incluye en la tabla 6. No se han encontrado diferencias entre estas fases que se puedan admitir como significativas ( $p>.05)$ en las partidas: \% de Deuda del Estado / d. total, y en los \% de deuda segregada y no segregada sobre la deuda total. Pero sí que aparece una diferencia altamente significativa $(\mathrm{p}<.01)$ el \% de deuda pública circulación / PIB, equivalente a un tamaño del efecto muy grande, y tal que los valores medios se incrementan con la secuencia de años, desde la fase expansiva a la de recesión y desde ambas, en especial hasta la fase recuperación (fig. 1).

\subsection{Análisis Exploratorio, Descriptivo y Comparativo de los instrumentos de financiación de la deuda pública en España. Periodo 1996-2015.}

Al igual que el apartado anterior, es necesario primero explicar los conceptos los conceptos a analizar. Así:

- Las Letras, Bonos y Obligaciones son instrumentos de financiación pública, cuya diferencia radica en el vencimiento de la obligación. Las letras tienen una estimación de vida de hasta 18 meses, los bonos van de 3 a 5 años y las Obligaciones hasta 30-50 años.

- Principal segregado de Bonos y Obligaciones. Según el artículo 1.c) del Real Decreto 38/1998 un Principal segregado es Valor con rendimiento implícito procedente del flujo de caja correspondiente al principal de un Bono segregable.
Figura 1: Diagrama de Caja. Distribución del \% de Deuda Pública Circulación / PIB, en función de la Fase económica

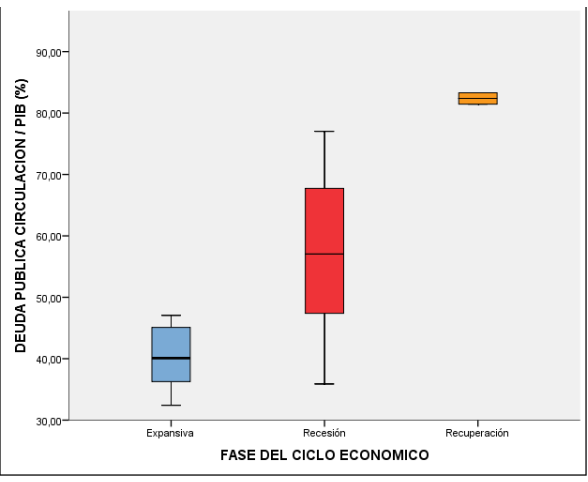

Elaboración propia mediante IBM SPSS Statistics 23

- Cupones de Bonos y Obligaciones. Según el artículo 1.e) del Real Decreto 38/1998 un cupón segregado: Valor con rendimiento implícito procedente del flujo de caja correspondiente a un cupón de un Bono u Obligación segregable.

- Pagarés de CCAA, y los Bonos y Obligaciones de CCAA. Las comunidades autónomas, corporaciones locales $\mathrm{y}$ diversos entes públicos emiten valores a corto plazo (pagarés) y a largo plazo. Sus características son similares a las de las Letras del Tesoro y los bonos y obligaciones del Estado, respectivamente.

- Restantes emisiones de deuda. Incluye el resto de las emisiones de la deuda pública. Incluye las emisiones especiales de deuda para los rescates bancarios.

- Valores de otros Estados. Deuda emitida para proceder al rescate de otros Estados miembros de la UE como Grecia, Irlanda o Portugal. 
Realizada esta aclaración, el análisis exploratorio y descriptivo pormenorizado de los instrumentos de financiación de deuda pública muestran los siguientes resultados:

Tabla 7: Análisis exploratorio y descriptivo. Instrumentos de financiación del Estado Español.

\begin{tabular}{|c|c|c|c|c|c|c|c|c|}
\hline \multirow{2}{*}{ Partida } & \multicolumn{2}{|c|}{ Centralidad } & \multirow{2}{*}{$\begin{array}{c}\text { Rango } \\
\text { (Mín. / Máx.) }\end{array}$} & \multicolumn{2}{|c|}{ Variabilidad } & \multirow{2}{*}{ Asimetría } & \multirow[b]{2}{*}{ Curtosis } & \multirow{2}{*}{$\begin{array}{l}\text { Test SW: } \\
\text { p valor }\end{array}$} \\
\hline & Media & Mediana & & $\begin{array}{l}\text { Desviación } \\
\text { estándar }\end{array}$ & $\begin{array}{c}\text { Rango } \\
\text { intercuartil }\end{array}$ & & & \\
\hline Letras Tesoro & 58548.23 & 52608.17 & 31300.89 / 90607.58 & 23662.93 & 49068.76 & 0.26 & -1.82 & .005 \\
\hline $\begin{array}{l}\text { Bonos y } \\
\text { Obligaciones }\end{array}$ & 348680.17 & 252272.34 & 170063.15 / 705353.20 & 169931.35 & 251122.12 & 1.01 & -0.34 & .005 \\
\hline $\begin{array}{l}\text { Principales de } \\
\text { B. y O. }\end{array}$ & 18092.04 & 13537.27 & 7780.04 / 39630.80 & 9539.33 & 11902.36 & 1.36 & 0.74 & .001 \\
\hline $\begin{array}{l}\text { Cupones de } \\
\text { B. y O. }\end{array}$ & 12950.77 & 10438.97 & 4203.75 / 24793.53 & 6744.89 & 12412.48 & 0.65 & -1.13 & .021 \\
\hline Pagarés CC.AA. & 298.23 & 319.37 & 76.70 / 420.56 & 78.95 & 80.72 & -1.39 & 2.82 & .034 \\
\hline $\begin{array}{l}\text { Bonos y } \\
\text { Oblig. CC.AA. }\end{array}$ & 18502.86 & 15600.51 & 7387.25 / 34920.14 & 9218.87 & 15786.98 & 0.70 & -0.90 & .031 \\
\hline $\begin{array}{l}\text { Restantes } \\
\text { emisiones }\end{array}$ & 7042.15 & 4654.02 & $566.65 / 26264.40$ & 7060.06 & 10772.73 & 1.54 & 1.98 & .002 \\
\hline $\begin{array}{l}\text { Valores otros } \\
\text { estados }\end{array}$ & 8852.64 & 5019.99 & 10.00 / 28604.64 & 9732.33 & 12862.91 & 1.08 & -0.05 & .011 \\
\hline
\end{tabular}

Letras del Tesoro. Esta partida muestra un desvío significativo ( $\mathrm{p}<.01)$ con respecto al modelo normal, a pesar de su muy buen grado de simetría. En la evolución durante los años del estudio se aprecia una clara caída que se detiene en 2001, se mantiene estable sus valores hasta el 2007; desde ese punto se aprecian 2 años consecutivos con un incremento enorme que deja ya los valores muy por encima de la media para el resto de la serie aunque con constantes fluctuaciones. Ver figura 2.

Bonos y Obligaciones. También se ha encontrado que la partidas se desvía significativamente $(\mathrm{p}<.01)$ de la normal, aunque en este caso sí que observa una tendencia asimétrica positiva. En la evolución a lo largo de los años (fig. 3) se aprecia de forma casi constante una tendencia alcista, que tiene una mayor pendiente a partir del año 2009.

Principales de Bonos y Obligaciones. Esta partida se comporta de forma bastante similar a la anterior, tanto en la asimetría positiva, como en el desvío significativo $(\mathrm{p}<.01)$ sobre la curva normal, como en la tendencia alcista a lo largo de los años (fig. 4) mucho más acentuada desde el año 2010 en este caso.

Cupones de Bonos y Obligaciones. De nuevo se aprecian valores cuya distribución tiene cierta similitud con las dos anteriores, en cuanto a la evolución permanente al alza (fig. 5). En el año 2011 se muestra el mayor salto en la serie, aunque en este caso la asimetría es negativa y el desvío con respecto al modelo de la normal es leve $(\mathrm{p}<.05)$ de modo que se podría hablar de una cierta tendencia hacia la normalidad.

Pagarés CC.AA. Se ha encontrado un desvío leve con respecto a la curva normal $(p<.05)$ aunque se ha observado una clara asimetría negativa. La variación a lo largo de los años es notablemente distinta a la de las partidas anteriores. En este caso, aunque con dientes de sierra se aprecia 
Figura 2: Diagrama de líneas. Deuda Letras del tesoro, por año.

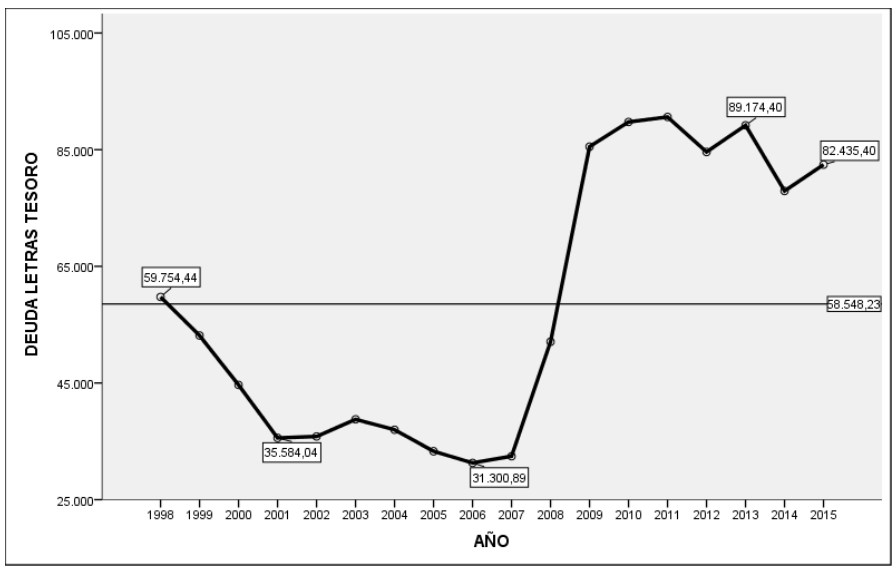

Elaboración propia mediante IBM SPSS Statistics 23

Figura 3: Diagrama de líneas. Deuda Bonos y Obligaciones, por año.

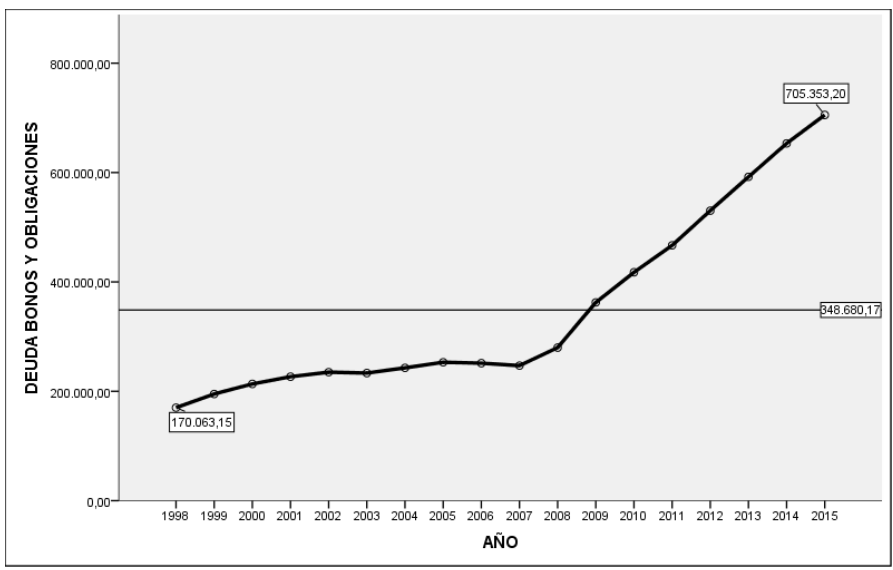

Elaboración propia mediante IBM SPSS Statistics 23

una cierta tendencia hacia la baja que culmina con una gran caída en el año 2010 para, a partir de él, volver a subir aunque sin llegar al valor medio de la serie (fig. 6).

\section{Bonos y Obligaciones CC.AA. De nuevo} se aprecia un desvío leve con respecto a la normalidad $(\mathrm{p}<.05)$. Por su parte la evolución a los largo de los años del estudio (fig. 7) se asemeja a algunas de las anteriores en tanto que muestra un incremento paulatino de los valores que es especialmente mayor a partir del año 2011. Restantes emisiones. Esta partida se aleja significativamente de la curva normal ( $p<.01)$ con una evidente asimetría positiva. En el estudio de su variación durante el periodo de estudio (fig. 8) se aprecia como los valores descienden lentamente desde el inicio hasta el 2008; momento en el cual se invierte la tendencia para proceder a una subida mucho mayor que los descensos anteriores, distinguiéndose con el pico más alto en el año 2013, tras el 
Figura 4: Diagrama de líneas. Deuda de Principales de Bonos y Obligaciones, por año.

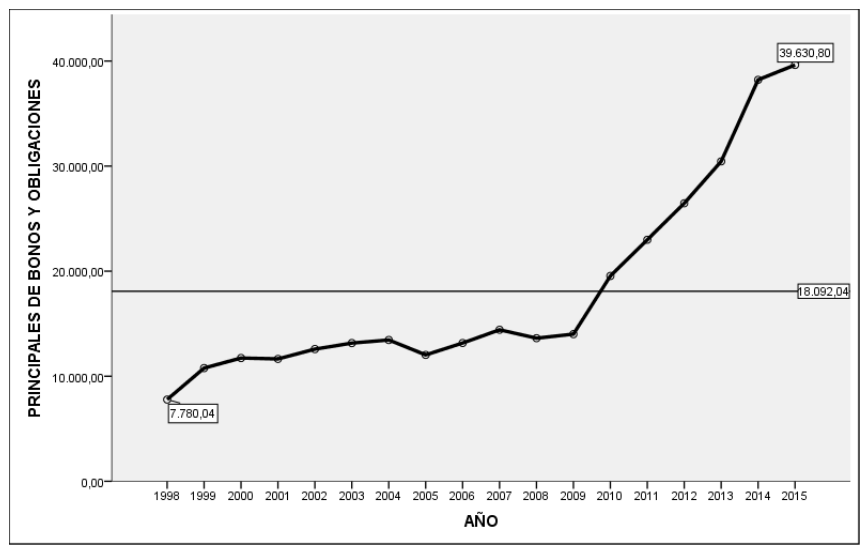

Elaboración propia mediante IBM SPSS Statistics 23

Figura 5: Diagrama de líneas. Deuda de Cupones de Bonos y Obligaciones, por año.

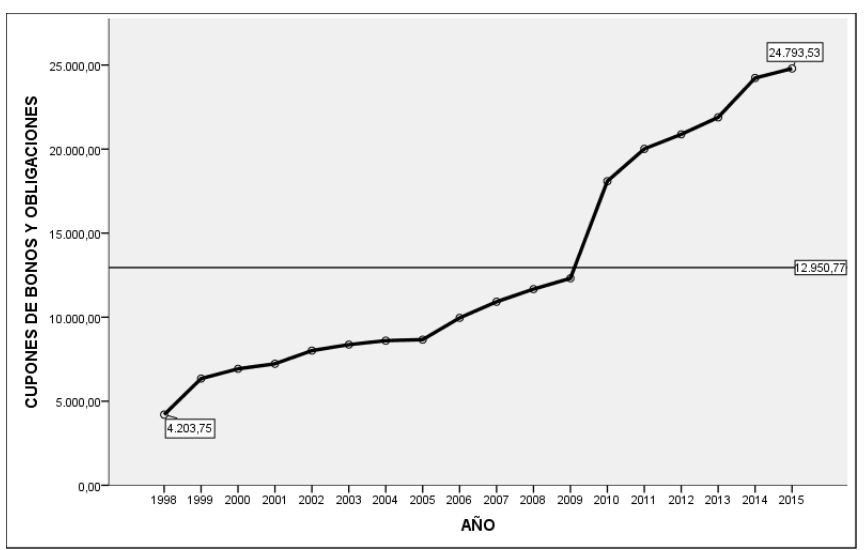

Elaboración propia mediante IBM SPSS Statistics 23

Figura 6: Diagrama de líneas. Deuda de Pagarés CC.AA., por año.

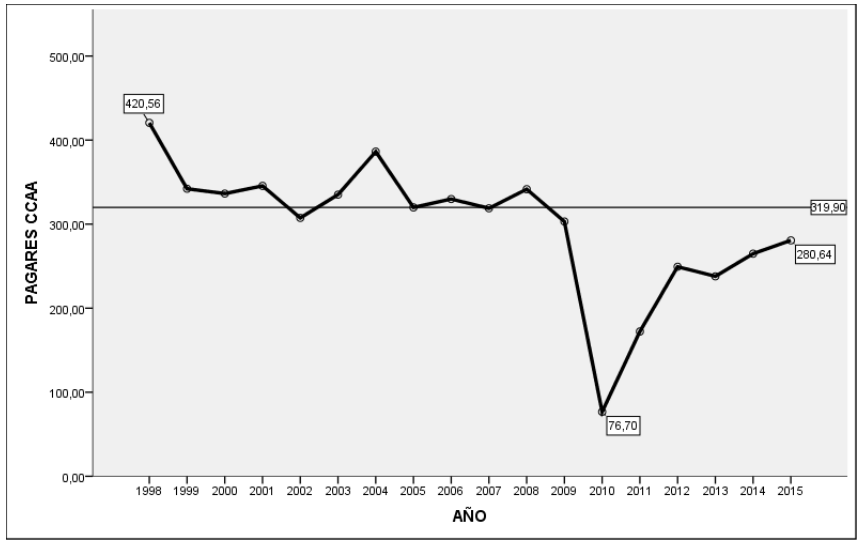

Elaboración propia mediante IBM SPSS Statistics 23 
cual se inicia una nueva caída en los dos últimos años.

Valores otros Estados. La partida tiene un cierto desvío $(p<.05)$ con respecto a la curva normal de Gauss. El estudio de su variación anual (fig. 9) presenta de forma muy clara una subida desde el inicio que se acentúa con una gran pendiente desde el 2004 hasta los picos de los 2007-2008, desde donde cae tan rápido como subió, hasta llegar cerca de los valores iniciales.

En el siguiente bloque de resultados, se analizan las partidas de deuda expresadas en forma de porcentaje con respecto a la Deuda total. La tabla 8 contiene el resumen de la exploración y de los índices descriptivos que les corresponden a estas ratios.

Figura 7: Diagrama de líneas. Deuda de Bonos y Obligaciones CC.AA., por año.

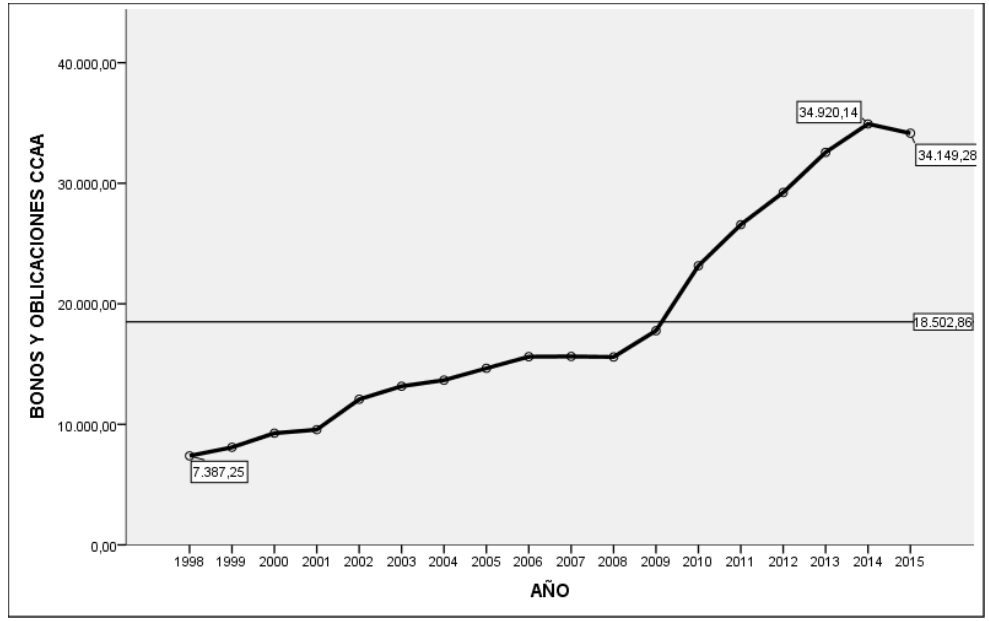

Elaboración propia mediante IBM SPSS Statistics 23

Figura 8: Diagrama de líneas. Deuda de restantes emisiones, por año.

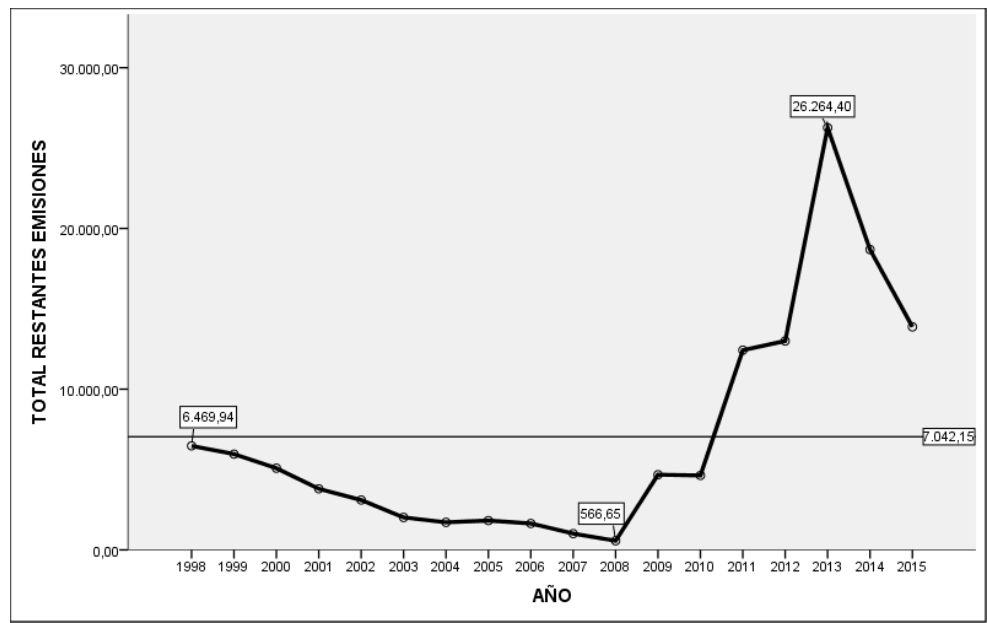

Elaboración propia mediante IBM SPSS Statistics 23 
Figura 9: Diagrama de líneas. Deuda de valores otros estados, por año.

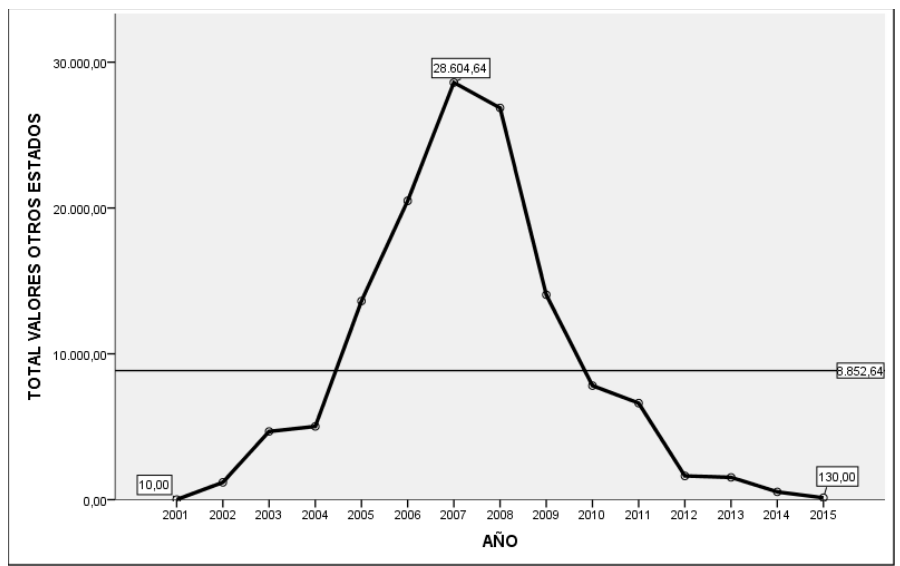

Elaboración propia mediante IBM SPSS Statistics 23

Tabla 8: Análisis exploratorio y descriptivo. Partidas Macroeconómicas: \% Letras, Bonos, Pagarés, etc. / D. Total

\begin{tabular}{|c|c|c|c|c|c|c|c|c|}
\hline \multirow{2}{*}{ Partida } & \multicolumn{2}{|c|}{ Centralidad } & \multirow{2}{*}{$\begin{array}{c}\text { Rango } \\
\text { (Mín. / Máx.) }\end{array}$} & \multicolumn{2}{|c|}{ Variabilidad } & \multirow{2}{*}{ Asimetría } & \multirow{2}{*}{ Curtosis } & \multirow{2}{*}{$\begin{array}{l}\text { Test SW } \\
\text { p valor }\end{array}$} \\
\hline & Media & Mediana & & $\begin{array}{l}\text { Desviación } \\
\text { estándar }\end{array}$ & $\begin{array}{c}\text { Rango } \\
\text { intercuartil }\end{array}$ & & & \\
\hline $\begin{array}{l}\text { \% Letras Tesoro / } \\
\text { Deuda total }\end{array}$ & 13.01 & 12.03 & $9.10 / 23.33$ & 3.81 & 5.65 & 1.34 & 1.89 & .021 \\
\hline $\begin{array}{l}\text { \% Bonos y Obligaciones / } \\
\text { D. Total }\end{array}$ & 73.37 & 73.79 & 66.41 / 78.32 & 3.09 & 4.70 & -0.48 & -0.08 & .835 \\
\hline $\begin{array}{l}\text { \% Principales de B. y O. / } \\
\text { D. Total }\end{array}$ & 3.80 & 3.84 & $2.74 / 4.51$ & 0.46 & 0.61 & -0.71 & 0.37 & .616 \\
\hline $\begin{array}{l}\text { \% Cupones de B. y O. / } \\
\text { Deuda Total }\end{array}$ & 2.67 & 2.71 & $1.64 / 3.12$ & 0.37 & 0.48 & -1.25 & 2.55 & .075 \\
\hline $\begin{array}{l}\text { \% Pagarés CC.AA. / } \\
\text { Deuda Total }\end{array}$ & 0.08 & 0.09 & $0.01 / 0.16$ & 0.04 & 0.09 & -0.13 & -1.10 & .105 \\
\hline $\begin{array}{l}\text { \% Bonos y Oblig. CC.AA. / } \\
\text { D. Total }\end{array}$ & 3.86 & 4.05 & $2.88 / 4.54$ & 0.51 & 0.78 & -0.82 & -0.43 & .048 \\
\hline $\begin{array}{l}\text { \% Restantes emisiones / } \\
\text { D. Total }\end{array}$ & 1.32 & 1.15 & 0.14 / 3.31 & 0.88 & 1.43 & 0.61 & -0.28 & .351 \\
\hline $\begin{array}{l}\text { \% Valores otros estados / } \\
\text { D. Total }\end{array}$ & 2.26 & 1.35 & $0.00 / 8.16$ & 2.70 & 3.85 & 1.21 & 0.21 & .005 \\
\hline
\end{tabular}

Las conclusiones que se pueden apreciar sobreelestudiodelosdatosson lassiguientes:

Tan sólo una partida muestra una desviación de forma significativa $(\mathrm{p}<.01)$ y es la partida de \% Valores otros Estados / D.T. muestra una muy clara una subida desde el inicio en especial desde el 2004 hasta el pico del 2007, desde donde cae igualmente rápido hasta volver a los valores iniciales. En relación a la partida de \% Letras del Tesoro / D.T. Se he encontrado un desvío leve aunque significativo $(\mathrm{p}<.05)$ con respecto a la campana normal, dónde se aprecia una fuerte caída que se detiene en 2001 y se mantiene hasta el 2007, momento en el que se produce una clara subida durante dos años, para volver a caer de nuevo hasta llegar a los valores anteriores. Y el resto de partidas - \% Bonos y Obligaciones / D.T., \% Principales de Bonos y Obligaciones / D.T, \% Cupones de Bonos y Obligaciones / D.T, \% Pagarés CC.AA D.T-, se distribuyen con un muy buen ajuste al modelo de la normal ( $p>05$ ), y en todos ellos se observa un incremento 
de todos los valores a partir del año 2007, aunque con algunas variaciones a la baja o al alza entre las medias, con un pico en 2009/2010 y del que se observa la tendencia de incremento hasta reposar en los dos últimos años.

A continuación se procede a contrastar los valores medios de las partidas anteriores en función del partido en el Gobierno durante este periodo de años.

Como señala Larraga (2008, p.101):

Al hacer una breve referencia histórica de la Deuda Pública española, se comprueba que en 1990 soportaba unos intereses del $14 \%$, tenía una vida media escasamente superior a dos años y se concentraba en torno a la emisión de Letras del Tesoro a 1 año (85\% del saldo vivo versus $15 \%$ en Bonos del Estado), con algunas emisiones de Bonos a 3 años y -en menor medida- de Bonos a 5 años. Las Obligaciones del Estado a 10 años eran casi testimoniales pues la prima de riesgo habría puesto un coste prohibitivo de suportar.

\section{Continúa Larraga:}

Asimismo, el diferencial de tipos de interés que existían en los primeros años de la década de los 90 respecto a los principales emisores públicos europeos (Francia y Alemania) podía oscilar entre los 400 y 650 puntos básicos. A modo de ejemplo, los Bonos del Estado español a 3 años soportaban en 1990 una TIR del 14,50\%, mientras que los Bunds alemanes se situaban en una TIR con una media próxima al 8,5\%. A finales de 2004 , el saldo vivo en Letras del Tesoro, Bonos y Obligaciones del Estado y otras financiaciones de menor entidad estaba en torno a los 319.000 millones de euros, y el diferencial respecto a Francia y Alemania prácticamente extinguido.
Es evidente que la entrada en la UME cambió la forma de financiación de España, y la concentración de la deuda pasó de las letras del Tesoro en favor de los bonos y obligaciones. También cambió los tenedores de la misma, de pequeños inversores y ahorradores a grandes inversores de capital. Este artículo mostrará la evolución reciente, de manera pormenorizada, de dichas partidas, tras las reformas acaecidas y teniendo en cuenta el partido político en el gobierno, para saber cuáles han sido los instrumentos más utilizados y en qué proporción se han ido ampliando.

Los resultados se resumen en la tabla 9 . Como se puede comprobar en ella, la media es siempre superior en los años de gobierno del PP en todas las partidas, con excepción de la última "Valores de otros Estados", donde es algo mayor en los años del PSOE. Sin embargo, las diferencias en casi ningún caso alcanzan significación estadística ( $p>$.05) y además sus respectivos tamaños del efecto no hace sospechar lo contrario. Sí que es posible hablar de una posible significación ( $p<.10$ en Student y $p<.05$ en MW) con tamaño del efecto moderado. En la partida "Restantes emisiones", estando la media en los años del PP más alta que en los del PSOE (fig. 2). Y sí que aparece significación estadística $(\mathrm{p}<.01)$ en los Valores de otros Estados, donde como ya se dijo la media es notablemente más alta en los años de gobierno del PSOE (fig. 3) se aprecia el tamaño del efecto muy grande.

Para finalizar se cierra este bloque de análisis con el contraste de las partidas en función de la fase del ciclo económico (tabla 10). Se han encontrado diferencias significativas (al menos para $\mathrm{p}<.05$ ) en casi todas las partidas, con la excepción de la última, la de Valores de otros estados ( $p>$.05) aunque en esta partida se aprecia una clara tendencia a la baja en los dos últimos años (fase de recuperación) que 
Tabla 9: Análisis comparativo. Test de deferencia entre las medias.

Partidas Macroeconómicas: Letras, Bonos, Pagarés, etc..., en función del Partido en el Gobierno

\begin{tabular}{|c|c|c|c|c|c|c|c|c|c|}
\hline \multirow{2}{*}{ Partida } & \multirow{2}{*}{ Categoría del Factor } & \multicolumn{3}{|c|}{ Valores descriptivos } & \multicolumn{2}{|c|}{ Student } & \multirow{2}{*}{ Efecto: $\mathbf{R}^{2}$} & \multicolumn{2}{|c|}{ Mann-Whitney } \\
\hline & & $\mathbf{N}$ & Media & D.E. & $/ \mathrm{t} /$ & $\mathbf{P}$ & & /Z/ & $\mathbf{P}$ \\
\hline \multirow{2}{*}{ Letras Tesoro } & Gobierno del PP & 10 & 60189.00 & 21588.94 & \multirow{2}{*}{0.32} & \multirow{2}{*}{$.753^{\mathrm{NS}}$} & \multirow{2}{*}{.006} & \multirow{2}{*}{0.44} & \multirow{2}{*}{$.696^{\mathrm{NS}}$} \\
\hline & Gobierno del PSOE & 8 & 56497.27 & 27421.50 & & & & & \\
\hline \multirow{2}{*}{ Bonos y Obligaciones } & Gobierno del PP & 10 & 375474.26 & 216013.87 & \multirow{2}{*}{0.74} & \multirow{2}{*}{$.471^{\mathrm{NS}}$} & \multirow{2}{*}{.033} & \multirow{2}{*}{0.71} & \multirow{2}{*}{$.515^{\mathrm{NS}}$} \\
\hline & Gobierno del PSOE & 8 & 315187.55 & 88472.85 & & & & & \\
\hline \multirow{2}{*}{ Principales de B. y O. } & Gobierno del PP & 10 & 20242.70 & 12210.68 & \multirow{2}{*}{1.07} & \multirow{2}{*}{.299 Ns } & \multirow{2}{*}{.067} & \multirow{2}{*}{0.53} & \multirow{2}{*}{$.633^{\mathrm{NS}}$} \\
\hline & Gobierno del PSOE & 8 & 15403.71 & 3798.53 & & & & & \\
\hline \multirow{2}{*}{ Cupones de B. y O. } & Gobierno del PP & 10 & 13287.90 & 8456.27 & \multirow{2}{*}{0.73} & \multirow{2}{*}{$.821^{\mathrm{NS}}$} & \multirow{2}{*}{.003} & \multirow{2}{*}{0.71} & \multirow{2}{*}{$.515^{\mathrm{NS}}$} \\
\hline & Gobierno del PSOE & 8 & 12529.37 & 4263.75 & & & & & \\
\hline \multirow{2}{*}{ Pagarés CC.AA. } & Gobierno del PP & 10 & 311.97 & 55.37 & \multirow{2}{*}{0.82} & \multirow{2}{*}{$.426^{\mathrm{NS}}$} & \multirow{2}{*}{.040} & \multirow{2}{*}{0.44} & O6ONS \\
\hline & Gobierno del PSOE & 8 & 281.05 & 102.91 & & & & & $.969^{100}$ \\
\hline Rot & Gobierno del PP & 10 & 19041.31 & 11978.21 & 027 & 77 & $0 \cap$ & 071 & \\
\hline Bonos y Obl. CC.AA. & Gobierno del PSOE & 8 & 17829.80 & 4582.07 & 0.27 & $.791^{100}$ & .005 & 0.71 & .515 \\
\hline Restantesemicinnes & Gobierno del PP & 10 & 9826.17 & 7933.17 & 04 & $059 \mathrm{NS}$ & 20 & 249 & 01 \\
\hline Restantes emisiones & Gobierno del PSOE & 8 & 3562.13 & 3901.41 & 2.04 & $.059^{*}$ & .206 & 2.49 & (012 \\
\hline Valoreso & Gobierno del PP & 10 & 1385.44 & 1589.34 & 400 & ${ }^{*}$ & $55-20>0>$ & 324 & $000 * *$ \\
\hline Vdivites otrus estaús & Gobierno del PSOE & 8 & 15386.44 & 9095.23 & 4.00 & .002 & (Jכ2 & 0.24 & .000 \\
\hline
\end{tabular}

N.S. $=$ NO significativo $(\mathrm{P}>05)^{*}=$ Significativo al $5 \%(\mathrm{P}<.05)^{* *}=$ Altamente significativo al $1 \%(\mathrm{P}<.01)$

Figura 2: Diagrama de Caja. Distribución de la Deuda de restantes emisiones, en función del Partido en el Gobierno

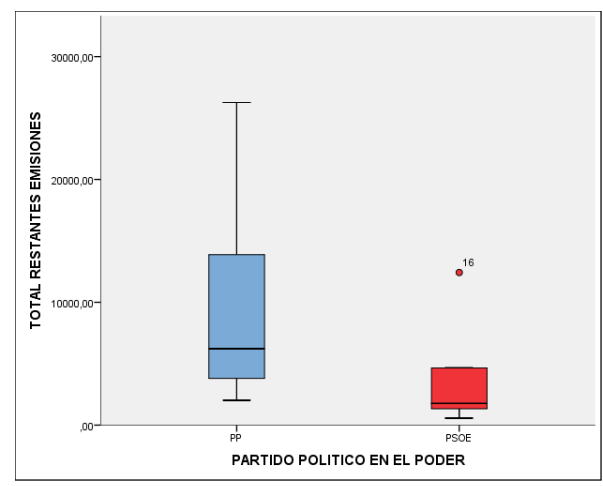

Elaboración propia mediante IBM SPSS Statistics 23

no alcanza la significación solo por el $\mathrm{N}$ de este subgrupo.

En las partidas donde sí hay significación, se ha observado que:

En Bonos y obligaciones ( $\mathrm{p}<.01)$, Principales de bonos y obligaciones $(p<.01)$, Cupones de bonos y obligaciones $(p<.01)$, Bonos y obligaciones de CC.AA ( $p<.01)$ y Restantes
Figura 3: Diagrama de Caja. Distribución de la Deuda de valores de otros estados, en función del Partido en el Gobierno

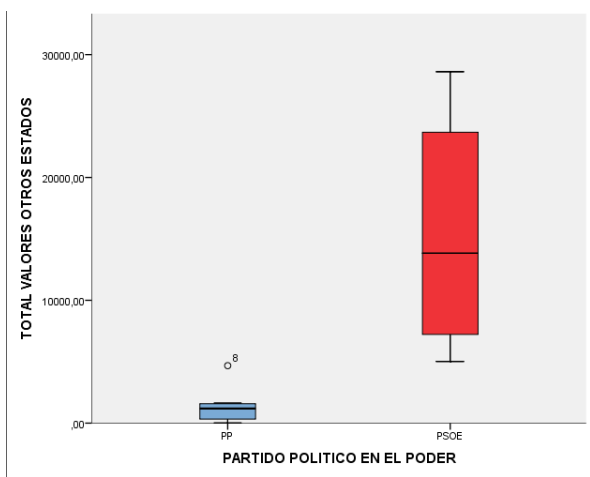

Elaboración propia mediante IBM SPSS Statistics 23

emisiones ( $\mathrm{p}<.05)$, los valores medios se han incrementado en los años de recesión con respecto a los de expansión, y de nuevo se vuelven a incrementar en la fase de recuperación con respecto a las anteriores (ver figuras que siguen). En el caso de las 4 primeras partidas citadas, el tamaño del efecto es muy grande (sobre .800), en tanto que la última es menor pero aún se mantiene como muy elevado. 
Tabla 10: Análisis comparativo. Test de deferencia entre las medias.

Letras, Bonos, Pagarés, etc..., en función de la Fase del ciclo económico

\begin{tabular}{|c|c|c|c|c|c|c|c|c|c|}
\hline \multirow{2}{*}{ Partida } & \multirow{2}{*}{ Categoría del Factor } & \multicolumn{3}{|c|}{ Valores descriptivos } & \multicolumn{2}{|c|}{ Anova } & \multirow{2}{*}{ Efecto: $\mathbf{R}^{2}$} & \multicolumn{2}{|c|}{ Kruskal-Wallis } \\
\hline & & $\mathrm{N}$ & Media & D.E. & $/ F /$ & $P$ & & $\mathrm{Chi}^{2}$ & $P$ \\
\hline \multirow{3}{*}{ Letras Tesoro } & Fase expansiva & 10 & 40176.79 & 9484.46 & \multirow{3}{*}{29.68} & \multirow{3}{*}{$.000^{* *}$} & \multirow{3}{*}{.798} & \multirow{3}{*}{11.69} & \multirow{3}{*}{$.003^{* *}$} \\
\hline & Fase de recesión & 6 & 81956.45 & 14835.27 & & & & & \\
\hline & Fase de recuperación & 2 & 80180.75 & 3188.55 & & & & & \\
\hline \multirow{3}{*}{ Bonos y Obligac. } & Fase expansiva & 10 & 226811.70 & 26837.36 & \multirow{3}{*}{43.64} & \multirow{3}{*}{$.000^{* *}$} & \multirow{3}{*}{.853} & \multirow{3}{*}{13.47} & \multirow{3}{*}{$.001^{* *}$} \\
\hline & Fase de recesión & 6 & 441594.27 & 113270.78 & & & & & \\
\hline & Fase de recuperación & 2 & 679280.18 & 36872.82 & & & & & \\
\hline \multirow{3}{*}{ Principales B. y O. } & Fase expansiva & 10 & 12073.13 & 1838.70 & \multirow{3}{*}{37.17} & \multirow{3}{*}{$.000^{* *}$} & \multirow{3}{*}{.832} & \multirow{3}{*}{12.39} & \multirow{3}{*}{$.002^{* *}$} \\
\hline & Fase de recesión & 6 & 21180.28 & 6757.05 & & & & & \\
\hline & Fase de recuperación & 2 & 28921.85 & 1002.61 & & & & & \\
\hline \multirow{3}{*}{ Cupones B. y O. } & Fase expansiva & 10 & 7923.67 & 1889.36 & \multirow{3}{*}{36.94} & \multirow{3}{*}{$.000^{* *}$} & \multirow{3}{*}{.831} & \multirow{3}{*}{13.47} & \multirow{3}{*}{$.001^{* *}$} \\
\hline & Fase de recesión & 6 & 17475.79 & 4432.65 & & & & & \\
\hline & Fase de recuperación & 2 & 24511.27 & 399.17 & & & & & \\
\hline \multirow{3}{*}{ Pagarés CC.AA. } & Fase expansiva & 10 & 344.19 & 34.23 & & & & & \\
\hline & Fase de recesión & 6 & 230.13 & 94.92 & 6.76 & $.008^{* *}$ & .474 & 9.13 & $.010^{*}$ \\
\hline & Fase de recuperación & 2 & 272.74 & 11.17 & & & & & \\
\hline & Fase expansiva & 10 & 11910.44 & 3113.77 & & & & & \\
\hline Bonos y Ob. CC.AA. & Fase de recesión & 6 & 24146.29 & 6595.44 & 28.02 & $.000^{* *}$ & .789 & 12.39 & $.002^{* *}$ \\
\hline & Fase de recuperación & 2 & 34534.71 & 545.08 & & & & & \\
\hline & Fase expansiva & 10 & 3262.93 & 1968.89 & & & & & \\
\hline Restantes emisiones & Fase de recesión & 6 & 10260.80 & 9221.21 & 5.98 & $.012^{*}$ & .443 & 6.04 & $.049^{*}$ \\
\hline & Fase de recuperación & 2 & 16282.33 & 3401.11 & & & & & \\
\hline & Fase expansiva & 10 & 10516.45 & 10786.27 & & & & & \\
\hline $\begin{array}{l}\text { Valores otros } \\
\text { estados }\end{array}$ & Fase de recesión & 6 & 9751.57 & 9576.01 & 0.94 & $.440^{\mathrm{NS}}$ & .128 & 3.62 & $.163^{\mathrm{NS}}$ \\
\hline & Fase de recuperación & 2 & 332.50 & 286.38 & & & & & \\
\hline
\end{tabular}

N.S. $=$ NO significativo $(\mathrm{P}>05)^{*}=$ Significativo al $5 \%(\mathrm{P}<.05)^{* *}=$ Altamente significativo al $1 \%(\mathrm{P}<.01)$

Figura 4: Diagrama de Caja. Distribución de la Deuda Letras Tesoro, en función de la Fase económica

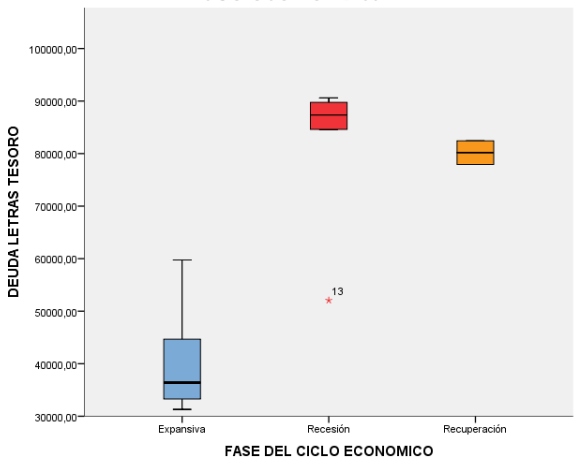

Elaboración propia mediante IBM SPSS Statistics 23
Figura 5: Diagrama de Caja. Distribución de la Deuda de Pagarés CC.AA., en función de la Fase económica

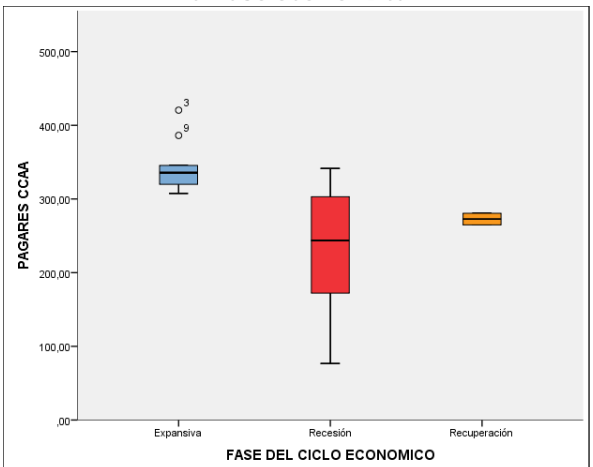

Elaboración propia mediante IBM SPSS Statistics 23 
En Letras del tesoro, la significación $(\mathrm{p}<.01)$ también corresponde a un tamaño del efecto muy grande (casi .800) pero la diferencia se debe a una media mucho menor en la fase de expansión con respecto a las otras dos, entre las que apenas habría cambios (Fig. 4).

Y finalmente, en Pagarés de las CC.AA. ( $p<.01$ y efecto grande) la diferencia, al contrario de la anterior, se debe a que el valor medio es superior en los años de la fase de expansión, con respecto al resto de los años (Fig. 5).

\section{DISCUSIÓN}

En el presente artículo se hizo un análisis de las partidas de deuda entre 1996-2015. La discusión del mismo no tiene que ver con las causas por la cuales la deuda pública aumentó, ni el papel del Banco Central Europeo en la emisión de la Deuda Pública, ni medir el impacto de las reformas el mercado de deuda español en 1997 y 2005, ni de si las mismas han provocado el aumento o disminución de las partidas o de evaluar las decisiones de la autoridad monetaria. Solo se muestran los resultados del mercado primario de deuda pública y a través de un breve recorrido histórico por los acontecimientos acaecidos durante los últimos veinte años -entrada en al UME y creación y modificación del nuevo mercado de deuda publica español-.

Los resultados que arroja el análisis descriptivo, muestran que las partidas de deuda -tablas 1 y 2- presentan un desvío altamente significativo con respecto a la normal (<.01). El resultado es similar cuando se realiza el estudio con partidas en relación al ratio -PIB y D. total-, pero en este caso, aunque el resultado es significativo, se tiende a la normalidad.
En el análisis comparativo, en el caso de las partidas de deuda -tablas 3 y 4 - en relación a los partidos políticos, las diferencias son estadísticamente significativas ( $p>.05)$ se muestra su evolución una variabilidad más alta con los gobiernos del PP. El análisis en ratio de las partidas, las medias también son superiores con los gobiernos del PP. Cuando se analiza las partidas de deuda en relación al Ciclo Económico -tablas 5 y 6- los resultados son estadísticamente significativos en todos los casos, estos son más altos en la época de recesión económica. Llama la atención la relación entre \% de deuda pública circulación / PIB, la significación es muy alta, así como el tamaño del efecto en la fase de recuperación.

En cuanto al análisis pormenorizado de los instrumentos de financiación del Estado Español muestra que el análisis descriptivo sobre los instrumentos de deuda pública -tablas 7 y 8-, se aprecia que las letras, bonos y obligaciones han tenido un desvío significativo $(\mathrm{p}<.01)$. Llama la atención que los pagarés de CCAA se acortan mientras que los bonos y obligaciones de las CCAA han ido aumentado desde 2011. También llaman la atención dos partidas "Restantes emisiones" que muestra el impacto del rescate bancario con su pico más alto en el 2013 y "valores de otros estados" con las emisiones de deuda para los rescates de otros países, con sus puntos más altos en 2007-2008. Cuando se analizan estas partidas con los ratios -PIB, D. Total-, el desvío es leve aunque significativo con respecto a la normal, observándose un aumento de todos los valores a partir de 2007, con picos alcistas en 2009-2010. En cuanto a su relación con el partido político -tabla 9-, las medias son siempre superiores con los gobiernos del PP, excepto en "Valores de otros Estados", donde es algo mayor en los años del PSOE, ello es debido a que el mayor gasto se produjo cuando 
gobernaba el PSOE. Lo mismo ocurre con la partida de "Restantes emisiones", así la media en los años del PP es más alta y ello es debido a que coincidió con el Rescate bancario. Por último, en relación al Ciclo Económico -tabla 10-, en la fase de recisión y recuperación se han incrementado los Letras, Bonos y Obligaciones, Principales de bonos y obligaciones, Cupones de bonos y obligaciones, Bonos y obligaciones de CC.AA y Restantes emisiones.

Los resultados que se han mostrado podrían ser tenidos en cuenta para la formulación de políticas de deuda públicas y observar como no ha sido racional el lineamiento político del PP, partido de ideología liberal-conservador. Los resultados que se ofrecen pueden servir de base para futuras investigaciones que ayuden a comprender y brinden señales de los problemas de endeudamiento español desde los últimos veinte años.

\section{REFERENCIAS BIBLIOGRÁFICAS}

Álvarez-Nogal, Carlos (2015) "Historia de la Deuda Pública en España”. Madrid. Estudios Históricos. 397p.

Arrizabalo Montoro, Xavier (2014). "Capitalismo y Economía Mundial”. España. Instituto Marxista de Economía (IME), 719p.
Dominguez, Jose M., Lopez del Paso, Rafael (2011) "Situaciones de impago de la deuda soberana". Revista Exitocos. Vol. 4 Diciembre. P. 147-152.

Hinkle DE, Wiersma W, Jurs SG. (2003) "Applied Statistics for the Behavioral Sciences". EE.UU. 5th ed. Boston: Houghton Mifflin. p.756.

Larraga, Pablo; Mercado Monetaria y mercado de renta fija. Conocimiento de los dos grandes mercados para entender las valores del resto de mercados financieros. Profit. Barcelona. 2008. p. 378.

Piketty, Thomas. "El capital en el siglo XXI". Primera edición en español (2014). España. Fondo de Cultura Económica de España, p. 641.

Reinhart, Carmen y Kenneth, Rogoff (2011). "Esta Vez es Distinto: Ocho Siglos de Necedad Financiera". México, Fondo de Cultura Económica de España, 464p.

Sack, Alesander N (1927). "Les effets des transformations des états sur leurs dettes publiques et autres obligations financiéres". Trataite juridique et financier. Volumen I-Dettes Publiques. Paris. 182p.

Monge-Antolín V. (2016). Evolución y análisis de la deuda pública en España. Periodo 19962015. Panorama Económico, 24, 49-70. 